\title{
O Status da Declaração Universal dos Direitos Humanos no Direito Internacional Contemporâneo
}

\author{
The Status of the Universal Declaration of Human Rights in \\ Contemporary International Law
}

\begin{abstract}
Resumo: É geralmente reconhecido que a Declaração Universal dos Direitos Humanos é um dos documentos mais importantes do século XX, tendo sido traduzida para mais de 300 línguas. $\mathrm{O}$ mero fato que os diversos países concordaram em 1948 com o seu texto, estipulando uma série de direitos que todos os seres humanos devem gozar e cuja promoção e garantia são a responsabilidade de todos os Estados é, em si mesmo, um sucesso inédito na história. Assim sendo, o propósito deste texto é rever a importante influência desta Declaração no direito internacional contemporâneo e verificar o seu lugar e o seu status jurídico neste campo.

Palavras-chave: Declaração Universal dos Direitos Humanos. Direito Internacional Contemporâneo. Status Jurídico.
\end{abstract}

Brian D. Lepard 1

\begin{abstract}
It is generally recognized that the Universal Declaration of Human Rights is one of the most important documents of the 20th century, having been translated into more than 300 languages. The mere fact that diverse nations agreed in 1948 on its text, specifying a series of rights that all human beings must enjoy and that all States must promote and guarantee is, in itself, an unprecedented success in history. Accordingly, the purpose of this article is to review the important influence of this Declaration on contemporary international law and to clarify its place and legal status in this field.
\end{abstract}

Keywords: Universal Declaration of Human Rights. Contemporary International Law. Juridical Status.

\section{Introdução}

É geralmente reconhecido que a Declaração Universal dos Direitos Humanos (DUDH) é um dos documentos mais importantes do século XX. ${ }^{2}$

\footnotetext{
${ }^{1}$ Harold W. Conroy Professor da Faculdade de Direito - University of Nebraska (Estados Unidos).

2 Por exemplo, escrevendo em 1999, na ocasião do quinquagésimo aniversário da Declaração, Elsa Stamatopoulou, Yael Danieli, e Clarence Dias afirmaram que "[a] inclusão, em 1945, de direitos humanos na Carta da ONU como um dos propósitos básicos da Organização e a adoção da Declaração Universal dos Direitos Humanos em 1948 são marcos na história de milhões de vítimas buscando justificação moral" (STAMATOPOULOU; DANIELI; DIAS, 1999, p. 9 - tradução livre).
} 
Ela é talvez o documento mais traduzido na história, tendo sido publicado em mais de 500 línguas. ${ }^{3}$ O mero fato que os Estados diversos no mundo podiam concordar em 1948 sobre o texto de uma declaração de direitos humanos de que todos os seres humanos devem gozar - e que estes mesmos Estados devem promover e garantir - é em si mesmo um sucesso inédito na história. É um fato especialmente impressionante tendo em vista a grande diversidade de ideologias no mundo na época, a realidade que estas ideologias divergentes produziram as guerras mais destrutivas que o mundo já havia presenciado, e as violações rampantes destes mesmos direitos que haviam sido cometidas por parte de muitos Estados até lá.

Ademais, ao longo das sete décadas passadas de lá para cá, a DUDH tem crescido em importância, sendo referenciada constantemente, inclusive em diversas constituições, leis, declarações internacionais e tratados internacionais. O seu peso tem sido sentido não apenas no campo do direito, mas também na cultura geral e na esfera moral. Muitas organizações nãogovernamentais têm sido criadas com a missão de promover os direitos proclamados neste documento reverenciado.

Neste texto o meu propósito é rever a importante influência da DUDH sobre o direito internacional contemporâneo e aprofundar o seu status e lugar neste direito. Por necessidade, esta revisão pode apenas tocar a superfície do assunto e oferecer um panorama geral sobre a influência e o status jurídico da Declaração. Primeiro, o artigo recapitula brevemente a história da adoção da DUDH depois da criação das Nações Unidas em 1945, há 75 anos. Na sequência, ele revê a influência moral e política da DUDH, que fortalecem a sua influência jurídica. O artigo, então, se torna a este assunto especificamente, revisando os vários meios pelos quais a DUDH tem influenciado muitas fontes de direito, tanto ao nível nacional quanto ao nível internacional. Depois, o artigo investiga o status jurídico da DUDH em si

\footnotetext{
${ }^{3}$ Veja https://ohchr.org/EN/UDHR/Pages/WorldRecord.aspx.
} 
mesma, começando com uma exploração do status original da Declaração em 1948.

O texto então propõe um método novo para determinar como interpretar os tratados, identificar normas de direito internacional consuetudinário e estabelecer princípios gerais de direito - as três fontes principais do direito internacional. Este método, que eu tenho elaborado em outras obras, permite a consideração de "princípios éticos fundamentais". Eu utilizo esta teoria nova para aprofundar, primeiro, como a DUDH pode ser utilizada na interpretação da Carta das Nações Unidas. Na luz desta abordagem, o artigo apura também o status da Declaração como resolução da Assembleia Geral das Nações Unidas, tendo em vista o status concedido a resoluções da Assembleia pela Carta. Uma outra questão importante abordada pelo texto é o status dos direitos proclamados na DUDH como normas de direito internacional consuetudinário.

Esta questão leva outras mais específicas, tais como se a Declaração na sua integridade é agora uma parte do direito internacional consuetudinário, ou se por contraste somente alguns dos direitos proclamados no documento têm conseguido este status. O artigo também toca sobre a questão da relação entre a DUDH e os tão-chamados "princípios gerais de direito" e se todos os direitos humanos reconhecidos na Declaração possam ser considerados tais princípios. Finalmente, o artigo tenta de formar algumas conclusões breves sobre porque é essencial estabelecer o status jurídico preciso da DUDH no direito internacional contemporâneo usando o método que eu tenho proposto.

\section{O Nascimento da Declaração Universal dos Direitos Humanos}

Antes da adoção da Declaração, a ideia de que existem direitos humanos universais não foi reconhecida formalmente pelos governos, mesmo que nos círculos filosóficos alguns pensadores tivessem articulado, de 
vez em quando, as raízes do conceito. Começando com a adoção do texto do Pacto da Liga das Nações em 1919, nós podemos perceber o reconhecimento de vários direitos particulares que funcionaram como brotos que apareceram antes da floração plena da ideia. Portanto, o Pacto deu à Liga o poder de supervisar a execução de acordos sobre o tráfico das mulheres e das crianças e deu a todo mundo o direito a condições de trabalho justas e humanas (LEAGUE OF NATIONS, 1919, art. 23[a][c]).

Ademais, a Liga, durante a sua existência, adotou tratados importantes entre seus membros poderosos e os países recentemente reconhecidos pela Liga visando à proteção das comunidades minoritárias nestes países. Por exemplo, o tratado com a Polônia, que serviu como modelo pelos outros, protegeu os direitos da comunidade judaica assim como a comunidade de falantes de alemão. ${ }^{4}$

Sem dúvida, as atrocidades cometidas durante a Segunda Guerra Mundial, e especialmente os horrores do Holocausto e a campanha gerada pelos Nazistas para exterminar o povo judaico, batiam a consciência dos líderes dos Países aliados. No entanto, durante a conferência de Dumbarton Oaks em 1944, que unia os líderes destes países, as delegações britânicas e soviéticas inicialmente se opuseram à inclusão de uma referência na Carta futura das Nações Unidas à promoção dos direitos humanos como um propósito da organização nova. Os líderes de outros aliados, incluindo os Estados Unidos, insistiram sobre o assunto, e eventualmente os líderes concordavam sobre uma provisão afirmando que as Nações Unidas devem "promover respeito pelos direitos humanos e liberdades fundamentais" (GOODRICH; HAMBRO; SIMONS, 1969, p. 371-374).

Na conferência de San Francisco, de junho de 1945, o assunto do papel dos direitos humanos na missão da organização foi abordado

\footnotetext{
${ }^{4}$ Tratado sobre as minorias entre os poderes principais aliados e associados (o Império britânico, Francia, Itália, Japão e os Estados Unidos) e Polônia, firmado a Versailles (28 junho 1919), disponível em inglês a http://www.forost.ungarisches-institut.de/pdf/191906283.pdf. A respeito da proteção da comunidade judaica, veja os arts. 8 e 11.
} 
novamente. Os grandes poderes vacilavam e não quiseram dar uma maior importância a este propósito, tendo em vista, por exemplo, a política de segregação racial dos Estados Unidos e a prática de colonialismo por parte dos aliados europeus.

Do outro lado, representantes de organizações não-governamentais agitavam em favor da inclusão dos direitos humanos como um proposito central da organização, reunidos por representantes de alguns estados menores, incluindo na América latina, que achavam que a Organização deveria ter o dever de prevenir atrocidades humanos no futuro. Ao final, os redatores da Carta foram convencidos a fazer a promoção dos direitos humanos uma fundação essencial da organização e o texto final fortaleceu as provisões sobre os direitos humanos do texto adotado a Dumbarton Oaks (GOODRICH; HAMBRO; SIMONS, 1969, p. 373; e LAUREN, 2011, p. 192193).

Como resultado das discussões em San Francisco, a Carta dá um lugar preeminente à promoção dos direitos humanos. Por exemplo, o preâmbulo da Carta afirma que todos os povos das Nações Unidas são resolvidos a "reafirmar a fé nos direitos humanos fundamentais do homem, na dignidade e no valor do ser humano, [e] na igualdade de direito dos homens e das mulheres" (UNITED NATIONS, 1945). Ademais, a Carta declara que as Nações Unidas têm como propósito primeiro a realização da “cooperação internacional para resolver os problemas internacionais de caráter econômico, social, cultural ou humanitário, e para promover e estimular o respeito aos direitos humanos e às liberdades fundamentais para todos, sem distinção de raça, sexo, língua, ou religião" (UNITED NATIONS, 1945, art. 1, para. 3).

O Artigo 55 da Carta afirma que as Nações Unidas (1945) têm o dever de promover "o respeito universal por, e a realização de, direitos humanos e liberdades fundamentais para todos sem distinção de raça, sexo, língua, ou religião". O artigo 56 trata das obrigações dos Estados Membros das Nações 
Unidas, e afirma que eles "se comprometem a agir em cooperação" com a Organização "em conjunto ou separadamente" para realizar este fim (UNITED NATIONS, 1945). Este artigo representa uma elaboração do texto aprovado a Dumbarton Oaks, e os Estados participando na conferência de San Francisco acreditaram que esta linguagem fortaleceria este propósito das Nações Unidas (GOODRICH; HAMBRO; SIMONS, 1969, p. 371-373.)

Os redatores decidiram não especificar os direitos humanos na Carta. Em vez disso, eles concordaram que uma comissão de direitos humanos seria criada pelas Nações Unidas para elaborar um outro documento com esta função no futuro. $O$ texto final da Carta não referenciou uma declaração, mas criou um Conselho Econômico e Social - ECOSOC - que foi dotado do poder de fazer recomendações sobre os direitos humanos e formar uma Comissão de Direitos Humanos - CDH (UNITED NATIONS, 1945, art. 62, para. 2 e art. 68). Em fevereiro de 1946 o ECOSOC criou a CDH e lhe deu o dever de submeter proposições relatando a uma "afirmação internacional de direitos", que incluiria uma declaração, um tratado, e medidas de implementação (UNITED NATIONS, 1946; UNITED NATIONS, 1955, p. 2).

O presidente da CDH foi a "primeira dama” dos Estados Unidos, a Sra. Eleanor Roosevelt. ${ }^{5}$ A comissão fez várias pesquisas sobra a ideia dos direitos humanos e convidou muitos especialistas a contribuir com o projeto. Alguns dos membros mais importantes na elaboração da Declaração, além da Sra. Roosevelt, foram Sir John Humphrey, um canadense que foi o diretor da Divisão de direitos humanos estabelecida pelas Nações Unidas, e o francês René Cassin. Mas as contribuições de representantes de muitos outros países, incluindo países do "terceiro mundo," foram consideradas na redação do texto final (GLENDON, 2001, p. 221-233.) Não havia muito tempo para a Comissão completar o seu trabalho e acordar sobre o texto final da Declaração. Em 10 dezembro 1948, a Assembleia Geral das Nações

\footnotetext{
${ }^{5}$ Para uma história compreensiva da redação da DUDH, veja MORSINK, 1999.
} 
Unidas deu a sua aprovação à Declaração, adotando-a por uma votação de 48 votos em favor, zero contra, e 8 abstenções (UNITED NATIONS, 1950, p. 535). Atualmente esta data, o dia 10 dezembro, é celebrada como o 'Dia dos Direitos Humanos'.

A DUDH promove "o reconhecimento da dignidade inerente a todos os membros da família humana e dos seus direitos iguais e inalienáveis" (UNITED NATIONS, 1948, preâmbulo). E ela declara no seu primeiro artigo que: "[t]odos os seres humanos nascem livres e iguais em dignidade e direitos. Eles são dotados de razão e consciência e devem se comportar em relações com os outros num espírito de fraternidade" (UNITED NATIONS, 1948, art. 1).

De acordo com a Declaração, todos os humanos gozam de dois tipos de direitos: por um lado, os direitos "civis e políticos," e por outro lado, "direitos econômicos, sociais e culturais". A primeira categoria de direitos inclui, entre outros direitos, a liberdade da discriminação na base de raça, cor, sexo, língua, religião, opinião política, origem nacional ou social, fortuna, nascimento, ou qualquer outra situação; os direitos à vida, liberdade e segurança pessoal; a liberdade da escravatura ou servidão; a liberdade da tortura e outras penas ou tratamentos cruéis, desumanos, ou degradantes; o direito a ser reconhecido perante a lei e a proteção igual da lei; o direito a recursos judiciários justos e públicos e a ser julgado por um tribunal independente e imparcial; a liberdade de pensamento, de consciência e de religião; a liberdade de opinião e de expressão; e o direito de tomar parte no governo do seu pais, diretamente ou por intermédio de representantes livremente escolhidos (UNITED NATIONS, 1948, arts. 2-10, 18-19 e 21).

$\mathrm{Na}$ categoria de direitos econômicos, sociais, e culturais cita-se o direito à segurança social; o direito a trabalhar e a condições justas e favoráveis de trabalho e a proteção contra o desemprego; o direito a descanso e lazer; o direito a um padrão de vida adequada pela saúde e bemestar de uma pessoa e da sua família, incluindo alimentação, roupa, 
alojamento, cuidados médicos, e serviços sociais necessários; o direito à educação; e o direito a participar na vida cultural da sua comunidade (UNITED NATIONS, 1948, art. 22-27).

Logo depois da adoção da DUDH, a CDH começou o seu trabalho sobre a elaboração de um tratado protegendo os direitos humanos. Em pouco tempo ficou aparente que existiam diferenças graves entre os grandes poderes, particularmente os Estados Unidos e seus aliados, por um lado, e a União soviética e seus aliados, pelo outro. Estas diferenças foram o produto não apenas da "guerra fria" entre os superpoderes, mas da resistência de todos os Estados de firmar compromissos concretos e jurídicos concernentes ao tratamento dos seus próprios cidadãos.

Eventualmente os Estados Membros decidiram criar dois tratados para satisfazer as visões diferentes das duas grandes coalisões de Estados um tratado sobre os direitos civis e políticos (o Pacto Internacional sobre Direitos Civis e Políticos - PIDCP) e um outro sobre os direitos econômicos, sociais e culturais (o Pacto internacional sobre Direitos Econômicos, Sociais e Culturais - PIDESC). O texto destes tratados foi finalizado e aprovado pela Assembleia Geral em 1966, e cada tratado entrou em vigor dez anos depois, em 1976. Hoje em dia a maioria dos Estados Membros das Nações Unidas aderiu aos dois tratados. ${ }^{6}$

\section{A Influência Moral e Política da Declaração}

É claro que a Declaração tem exercido uma grande influência nos planos moral e político. De fato, a intenção original dos redatores da Declaração era de que ela seria um meio de promover a ideal moral de que toda pessoa possui uma dignidade inerente e direitos inalienáveis aliados a esta dignidade. $\mathrm{E}$ estes direitos também foram ligados à noção que todo o

\footnotetext{
${ }_{6}^{6}$ Em 19 de junho de 2020 têm-se 173 Estados aderentes ao PIDCP e 171 Estados aderentes ao PIDESC. Nesta data, 193 Estados são membros das Nações Unidas. Veja http://treaties.un.org e http://www.un.org/en/member-states/index.html.
} 


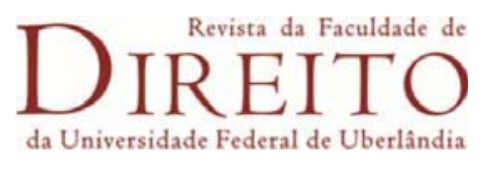

mundo forma parte de uma família humana que deve ser unida. Nas palavras da Declaração, ela foi definida como

[...] ideal comum a atingir por todos os povos e todas as nações, a fim de que todos os indivíduos e todos os órgãos da sociedade, tendo-a constantemente no espírito, se esforcem, pelo ensino e pela educação, por desenvolver o respeito desses direitos e liberdades e por promover, por medidas progressivas de ordem nacional e internacional, o seu reconhecimento e a sua aplicação universais e efetivos tanto entre as populações dos próprios Estados membros como entre as dos territórios colocados sob a sua jurisdição (UNITED NATIONS, 1948, preâmbulo).

As referências à Declaração feitas por líderes morais e éticos nos 72 anos que tem seguido a sua adoção são numerosas. Por exemplo, na ocasião do quinquagésimo aniversário da adoção da Declaração, Nelson Mandela, o famoso líder sul-africano, que lutava em favor dos direitos dos negros no seu País, dirigiu-se à Assembleia Geral das Nações Unidas, afirmando:

\begin{abstract}
Nascido depois da derrota do crime Nazi e fascista contra a humanidade, esta Declaração elevou alto a esperança que todas as nossas sociedades no futuro seriam construídas nas fundações da visão gloriosa soletrada em cada uma das suas cláusulas. [...] Para aqueles que tiveram que lutar por sua emancipação, tal como nós que, com o seu apoio, tivemos que nos liberar do sistema apartheid criminal, a Declaração universal dos direitos humanos serviu como a vindicação da justiça da nossa causa. Ao mesmo tempo, ela constituiu um desafio a nós que a nossa liberdade, uma vez atingida, deve ser dedicada à implementação das perspectivas contidas na Declaração. ${ }^{7}$
\end{abstract}

A Declaração tem inspirado inúmeras organizações nãogovernamentais que lutam para vocalizar o desespero de vítimas de violações de direitos humanos e para obter a justiça por estas vítimas. Por exemplo, a Anistia Internacional tira inspiração da Declaração no seu trabalho em favor dos direitos humanos e promove um conhecimento do documento, que a organização caracteriza como "um documento que age como um mapa das estradas global pela liberdade e pela igualdade". ${ }^{8}$

7 Citação disponível em https://www.thenation.com/article/nelson-mandelas-universaldeclaration-human-rights/ (tradução do autor).

8 Veja https://www.amnesty.org/en/what-we-do/universal-declaration-of-human-rights/. 
Mesmo na esfera política, líderes de governos têm invocada a Declaração em fazer argumentos concernentes à importância dos direitos humanos. Por exemplo, o Departamento de Estado dos Estados Unidas destaca a Declaração no seu site sobre os direitos humanos e a democracia, afirmando que

[a] proteção dos direitos fundamentais foi uma pedra de fundação no estabelecimento dos Estados Unidos há mais de 200 anos. Desde então, um objetivo central da política externa dos Estados Unidos tem sido a promoção do respeito aos direitos humanos, conforme consagrado na Declaração Universal dos Direitos Humanos. ${ }^{9}$

\section{A Influência Prática da Declaração Sobre Diversas Fontes de Direito}

$\mathrm{Na}$ esfera jurídica, a Declaração tem influenciado muitas fontes de direito diretamente e indiretamente. Basta citar apenas uns exemplos aqui. É aparente na história contada acima que a Declaração serviu como documento inspirador para centenas de tratados, declarações, e resoluções das Nações Unidas e seus órgãos nas sete décadas passadas.

Por exemplo, o propósito dos dois tratados mais importantes sobre os direitos humanos - o PIDCP e o PIDESC - foi transformar em direitos justiçáveis os direitos proclamados na Declaração, e por esta razão estes tratados dão testemunho à Declaração. Em cumprindo esta finalidade, o PIDCP afirma no seu preâmbulo que os Estados aderentes reconhecem "que, em conformidade com a Declaração Universal dos Direitos Humanos, o ideal do ser humano livre, no gozo das liberdades civis e políticas e liberto do temor e da miséria, não pode ser realizado, a menos que se criem as condições que permitam a cada um gozar de seus direitos civis e políticos, assim como de seus direitos econômicos, sociais e culturais" (UNITED NATIONS, 1966a, preâmbulo). ${ }^{10}$

\footnotetext{
9 Veja https://www.state.gov/j/drl/ - tradução livre.

10 No mesmo sentido, o PIDESC inclui uma provisão parecida no seu preâmbulo (UNITED NATIONS, 1966b, preâmbulo).
} 
Inúmeros outros tratados sobre os direitos humanos fazem referência à Declaração. Nós podemos citar como exemplo de um tratado recente a Convenção sobre os Direitos das Pessoas com Deficiência, que diz que os Estados aderentes reconhecem "que as Nações Unidas, na Declaração Universal dos Direitos Humanos e nos Pactos Internacionais sobre Direitos Humanos, proclamou e concordou que toda pessoa faz jus a todos os direitos e liberdades ali estabelecidos, sem distinção de qualquer espécie" (UNITED NATIONS, 2006, preâmbulo - item 'b’).

Outras declarações da Assembleia Geral das Nações Unidas ancoram os direitos que elas proclamam na DUDH. Muitas destas declarações tratam estes direitos proclamados na DUDH como existentes e reais por virtude da DUDH, não somente como direitos morais. Por exemplo, várias resoluções da Assembleia Geral concluíram que a África do Sul tinha violado suas obrigações sob a Carta e a Declaração, implicando uma visão da Assembleia Geral que a Declaração impõe obrigações jurídicas. ${ }^{11}$ Ademais, a Declaração dos direitos dos povos indígenas, adotada pela Assembleia Geral das Nações Unidas em 2007, afirma no seu primeiro artigo que "os indígenas têm direito, como povos ou como pessoas, ao desfrute pleno de todos os direitos humanos e liberdades fundamentais reconhecidos pela Carta das Nações Unidas, pela Declaração Universal de Direitos Humanos e o direito internacional relativo aos direitos humanos" (UNITED NATIONS, 2007, art. 1). Esta afirmação dá um status autoritário à Declaração ao lado da Carta ela-mesma e outras fontes de direito internacional.

Muitas declarações de órgãos especializados no campo de direitos humanos reafirmam os princípios na DUDH. Sem surpresa, as resoluções do Conselho de Direitos Humanos criado pelas Nações Unidas em 2006 quase sempre citam a DUDH em se tratando de situações envolvendo

\footnotetext{
${ }^{11}$ Veja, por exemplo, UNITED NATIONS, 1966c, preâmbulo.
} 
violações de direitos diversos e em países e regiões diferentes. ${ }^{12}$ Por exemplo, em 2018 o Conselho adotou uma resolução sobre assistência a Mali concernente aos direitos humanos na qual ele reafirmou "que todos os Estados têm a responsabilidade de promover, proteger e cumprir os direitos humanos e liberdades fundamentais entesourados na Carta, na Declaração Universal dos Direitos Humanos, nos Pactos internacionais sobre os direitos humanos e outros instrumentos de direitos humanos internacionais relevantes a quais eles são aderentes."13 Esta resolução parece dar uma força jurídica à Declaração ao coloca-la no mesmo plano que tratados obrigatórios e afirmar que todos os Estados no mundo têm a responsabilidade não apenas de promover, mas também de cumprir os direitos proclamados na Declaração.

Muitos documentos adotados por organizações regionais têm feito referência à Declaração e afirmam que o propósito deles é de implementar e realizar os direitos reconhecidos nela. Por exemplo, a Convenção Europeia dos Direitos Humanos, adotada em 1950, afirma que o propósito da Convenção é a execução dos direitos na DUDH que constituem direitos universais. O preâmbulo diz que os Estados fundadores foram "decididos, enquanto Governos de Estados Europeus animados no mesmo espírito, possuindo um patrimônio comum de ideais e tradições políticas, de respeito pela liberdade e pelo primado do direito, a tomar as primeiras providências apropriadas para assegurar a garantia coletiva de certo número de direitos enunciados na Declaração Universal' (grifo nosso) (CONSELHO DA EUROPA, 1950, preâmbulo). A respeito da Organização dos Estados Americanos, a Convenção Americana sobre Direitos Humanos também faz

\footnotetext{
12 Veja, por exemplo, as resoluções adotadas pelo Conselho durante 2017 e 2018, incluídas na Reportagem do Conselho de 2018, intitulada "Reportagem do Conselho dos Direitos Humanos" (UNITED NATIONS, 2018a).

13 Resolução do Conselho de Direitos Humanos no. 37/39, intitulada "Assistência técnica e a construção de capacidade para Mali no campo de direitos humanos," adotada o 23 de março de 2018, preâmbulo (UNITED NATIONS, 2018a, p. 141-145).
} 
referência à Declaração no seu preâmbulo (ORGANIZAÇÃO DOS ESTADOS AMERICANOS, 1969).

Virando às leis nacionais, um fenômeno muito impressionante é o reconhecimento da Declaração em muitas fontes de direito nacionais em todas partes do mundo. Este fenômeno testemunha a influência extraordinária da Declaração desde seu nascimento e o grau de sua penetração nos pensamentos jurídicos e morais de legisladores em torno do planeta.

Por exemplo, muitas constituições nacionais adotadas desde 1948 fazem referência à Declaração em alguma maneira. Segundo um estudo de constituições entreprendido em 1993, ao menos 90 constituições nacionais mencionaram a Declaração ou emprestaram frases tiradas dela (INTERNATIONAL LAW ASSOCIATION, 1994, p. 534). ${ }^{14}$ Uma busca atual no site constituteproject.org, que reproduz as constituições do mundo em 2020 , revela que 27 constituições hoje em dia fazem referência explicita à Declaração. ${ }^{15}$

Além disso, um número surpreendente destas constituições dá à Declaração um status jurídico no sistema jurídico nacional, um status que é muitas vezes superior às leis nacionais. Para dar um exemplo de uma tal provisão constitucional, a Constituição da República de Portugal afirma no art. 16 que "[o]s preceitos constitucionais e legais relativos aos direitos fundamentais devem ser interpretados e integrados de harmonia com a Declaração Universal dos Direitos do Homem" (PORTUGAL, 2006). Esta provisão confere à Declaração um papel interpretativo autoritário dentro da lei nacional.

Notavelmente, algumas constituições nacionais diretamente incorporam os direitos proclamados na Declaração na lei nacional. Por exemplo, a constituição de Andorra afirma simplesmente no seu art. 5 que

${ }_{14}$ Consulte as provisões constitucionais detalhadas reproduzidas em Hannum (1995-1996, p. 355-376 - em especial a discussão nas p. 313-315.

15 Veja http://constituteproject.org 
"a Declaração Universal dos Direitos Humanos é obrigatória em Andorra" (ANDORRA, 1993). Ademais, muitas leis nacionais fazem referência à Declaração de maneiras diversas ou emprestam alguma linguagem dela (INTERNATIONAL LAW ASSOCIATION, 1994, p. 535-536).

Por exemplo, nos Estados Unidos, o Congresso Federal tem adotado, primariamente na década dos anos setenta, leis visando a restringir o apoio financeiro e militar a países envolvidos em violações sérias de direitos humanos. Estas leis fazem referência aos direitos proclamados na Declaração. Nesse sentido, o Ato sobre sanções ao Iraque adotado pelo Congresso americano em 1990 declarou a visão do Congresso que o Iraque "é obrigado pelos pactos [de 1966], assim como a Declaração Universal dos Direitos Humanos, a respeitar os direitos internacionalmente reconhecidos" (UNITED STATES, 1990, §586F(a)(1)(2)). Cabe notar que o Congresso ainda afirmou que a Declaração impõe um tipo de obrigação jurídica sobre todos os Estados, incluindo o Iraque.

\section{O Debate sobre o Status Atual da Declaração no Direito Internacional}

Em virtude desta grande influência histórica e atual da Declaração sobre debates morais e políticos, e sobre todos estes níveis de direito, internacionais e nacionais, a Declaração hoje em dia pode ser considerada como a "Constituição" da ordem mundial dos direitos humanos. No entanto, apesar deste alto lugar moral e político ao qual ela é elevada, o status jurídico preciso da Declaração tem sido controvertido.

No plano jurídico formal, a Declaração faltou a força jurídica obrigatória quando ela foi adotada. Ela é uma resolução da Assembleia Geral das Nações Unidas, e as resoluções dela são apenas recomendações aos Estados Membros da Organização segundo o texto claro da Carta das 


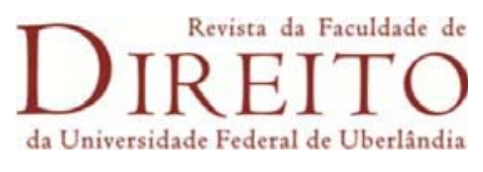

Nações Unidas. ${ }^{16}$ A Sra. Eleanor Roosevelt, conforme explanado acima, que liderava a Comissão de Direitos Humanos que adotou o texto do documento, enfatizou que "[e]la não é e não pretende ser uma afirmação de direito ou de obrigação jurídica" (LAUTERPACHT, 1968, p. 399).

Ademais, alguns representantes dos governos participando na elaboração do texto da Declaração afirmaram que a Declaração possui apenas autoridade moral, e não jurídica. Por exemplo, o representante da Nova Zelândia disse que "a Declaração, conforme uma afirmação de princípios, teve só a força moral" (UNITED NATIONS, 1950, p. 531). E em 1950 o estimado jurista Hersch Lauterpacht (1968, p. 419-420) afirmou que "Há nada na Declaração [...] que inclui - ou implica - qualquer limitação da liberdade dos Estados. Ela deixa essa liberdade não restringida". O argumento foi feito também que o plano original foi elaborar um tratado obrigatório ao lado da Declaração, o que estabelece que a Declaração não pode impor obrigações de uma natura jurídica. Apoiando este ponto de vista, John Humphrey (1976, p. 529) afirmou que "se a Declaração foi intencionada ser obrigatória, um tratado teria sido desnecessário".

No entanto, durante as sete décadas passadas, numerosos especialistas têm discutido a possibilidade que a Declaração tenha ficado uma interpretação autoritária das provisões da Carta das Nações Unidas tratando dos direitos humanos, tenha conseguido o nível de direito internacional consuetudinário por virtude de sua aceitação quase universal nas práticas e opiniões dos Estados, ou reflete princípios gerais de direito

16 Veja Carta das Nações Unidas, afirmando que a "Assembleia Geral poderá discutir quaisquer questões ou assuntos que estiverem dentro das finalidades da presente Carta ou que se relacionarem com as atribuições e funções de qualquer dos órgãos nela previstos e, com exceção do estipulado no artigo 12 , poderá fazer recomendações aos membros das Nações Unidas ou ao Conselho de Segurança ou a este e àqueles, conjuntamente, com referência a qualquer daquelas questões ou assuntos" (UNITED NATIONS, 1945, art. 10). Veja também art. 13, para. 1 (declarando que a "Assembleia Geral iniciará estudos e fará recomendações, destinados a: [...] b) promover cooperação internacional nos terrenos econômico, social, cultural, educacional e sanitário e favorecer o pleno gozo dos direitos humanos e das liberdades fundamentais, por parte de todos os povos, sem distinção de raça, sexo, língua ou religião" (UNITED NATIONS, 1945, art. 13, para. 1). 
quase globalmente reconhecidos - estes status jurídicos correspondendo às três fontes principais de direito internacional reconhecidas no estatuto da Corte Internacional de Justiça no seu artigo 38 (UNITED NATIONS, 1945 anexo).

O artigo 38 afirma, em parte, que "[a] Corte, cuja função seja decidir conforme o direito internacional as controvérsias que sejam submetidas, deverá aplicar: as convenções internacionais, sejam gerais ou particulares, que estabeleçam regras expressamente reconhecidas pelos Estados litigantes; o costume internacional como prova de uma prática geralmente aceita como direito; os princípios gerais do direito reconhecidos pelas nações civilizadas; as decisões judiciais e as doutrinas dos publicitários de maior competência das diversas nações, como meio auxiliar para a determinação das regras de direito, sem prejuízo do disposto no Artigo 59" (UNITED NATIONS, 1945 - anexo). Ao mesmo tempo, alguns acadêmicos têm argumentado que a Declaração não possui nenhuma força jurídica em si mesma. ${ }^{17}$

Como estes debates devem se resolver? Não é possível, claramente, conseguir conclusões definitivas, mas em minhas pesquisas tenho elaborado uma abordagem a questões tais como a intepretação dos tratados, a formação do direito internacional consuetudinário, e a identificação de princípios gerais de direito, que pode nos ajudar a atingir compreensões novas.

\section{Uma Abordagem Nova à Interpretação de Fontes de Direito Internacional}

Eu tenho elaborado nos meus livros uma abordagem nova à interpretação das três fontes principais do direito internacional - tratados, o direito consuetudinário e os princípios gerais de direito. Em geral, eu tenho sugerido que esta interpretação deve ser baseada em 'princípios éticos

${ }^{17}$ Veja, por exemplo, KELLY, 2000, p. 486-491. 
fundamentais'. Estes são princípios que tem sido reconhecido por Estados no direito internacional contemporâneo, incluindo na Carta das Nações Unidas e na Declaração Universal dos Direitos Humanos, e também que são logicamente relacionados a um princípio preeminente da "unidade na diversidade" (LEPARD, 2002).

Este princípio estabelece que todos humanos devem ser moralmente unificados como membros de uma única família no mesmo tempo que eles podem ter orgulho nas suas próprias origens e identidades diferentes, sejam elas étnicas, raciais, sociais ou culturais (LEPARD, 2002, p. 33-34). Este princípio tem apoio, por exemplo, no primeiro artigo da DUDH, que afirma que "Todos os seres humanos nascem livres e iguais em dignidade e em direitos. Dotados de razão e de consciência, devem agir uns para com os outros em espírito de fraternidade” (UNITED NATIONS, 1948, art. 1.). Este princípio também encontra apoio nas escrituras santas das maiores religiões do mundo, um apoio que lhe dá mais credibilidade como base de um sistema novo de interpretação das fontes do direito internacional (LEPARD, 2002, p. 45-50).

Outros princípios éticos fundamentais logicamente relacionados ao princípio da unidade na diversidade, e reconhecidos no direito internacional contemporâneos, incluem, por exemplo, a dignidade humana e os direitos humanos; a autonomia significativa pelos Estados, moderada por limitações sobre a soberania dos Estados e por uma teoria de governo baseada sobre a ideia de que o propósito do governo seja proteger e promover o bem-estar dos seus cidadãos; a liberdade das pessoas de fazer escolhas morais; a punição de criminosos; a resolução de problemas por um procedimento de consulta com mente aberta entre as pessoas ou estados afetados; o reconhecimento de uma comunidade global de Estados e pessoas comprometida a promover estes princípios éticos; e o dever de cumprir obrigações em tratados internacionais (LEPARD, 2010, p. 81-92). 
Quanto à interpretação das fontes tradicionais de direito internacional à luz destes princípios, eu tenho proposto que os tratados devem ser interpretados segundo as regras reconhecidas na Convenção de Viena sobre o Direito dos Tratados, que põem a ênfase sobre o sentido comum de palavras à luz dos objetivos e fim do tratado (UNITED NATIONS, 1969, art. 31), mas se existem dúvidas sobre este sentido, deve ser preferida uma interpretação que promove a realização de princípios éticos fundamentais (LEPARD, 2002, p. 102-103 e 113-118.)

Com respeito ao direito internacional consuetudinário, tenho sugerido, conforme explicado abaixo, uma nova abordagem que também leva em conta princípios éticos fundamentais. $\mathrm{E}$ quanto à identificação de princípios gerais do direito, tenho proposto que estes princípios não só podem incluir princípios de direito nacionais compartilhados entre as nações do mundo, mas também princípios gerais de direito internacional assim como princípios gerais de direito moral. Alguns princípios éticos fundamentais podem qualificar como esta terceira categoria de princípios gerais de direito moral, particularmente quando elas têm uma importância grande e encontram apoio dentro das grandes tradições filosóficas e religiosas do planeta (LEPARD, 2002, p. 105-110).

Torno agora à avaliação do papel da Declaração em relação à Carta das Nações Unidas como tratado, ao direito internacional consuetudinário, e aos princípios gerais de direito. Eu tento de esclarecer este papel levando em conta a abordagem explicada acima.

\section{A Declaração Como uma Interpretação Autoritária das Provisões da Carta das Nações Unidas sobre os Direitos Humanos}

Conforme a análise anterior, eu tenho proposto que as provisões da Carta devem ser interpretadas segundo os princípios de interpretação de tratados delineados na Convenção de Viena sobre o Direito dos Tratados, 
suplementados pela consideração do impacto de princípios éticos fundamentais. Portanto, em primeiro lugar, nós devemos determinar se uma provisão da Carta tem um sentido comum à luz dos objetivos e propósitos da Carta. Em segundo lugar, nós devemos averiguar os entendimentos verdadeiros compartilhados pelos Estados aderentes na época da adoção da Carta. O texto analisado no primeiro passo pode nos fornecer muitas provas destes entendimentos, mas nós podemos também fazer referência a medidas suplementares de interpretação, incluindo os pontos de vista exprimidos por Estados durante a elaboração da Carta. ${ }^{18}$

E em terceiro lugar, nós podemos indagar se existem entendimentos novos entre os Estados aderentes que alteram o sentido comum da Carta ou os entendimentos originais dos Estados aderentes. Tais entendimentos novos devem prevalecer na medida em que eles são igualmente ou mais consistentes com princípios éticos fundamentais. Finalmente, se existem ambiguidades restantes, nós devemos favorecer interpretações da Carta que ajudam o melhor a realizar princípios éticos fundamentais (LEPARD, 2002, p. $115-117$ e $126-127)$.

Existem muitas provas de que a Declaração reflete tais entendimentos novos do sentido da Carta, ambos na época da adoção da Carta assim como atualmente. Nós podemos encontrar provas destes entendimentos no próprio texto da Declaração. Cabe ressaltar que o preâmbulo da Declaração relembra que os Estados Membros das Nações Unidas se comprometeram na Carta a "promover, em cooperação com a Organização das Nações Unidas, o respeito universal e efetivo dos direitos do Homem e das liberdades fundamentais". E o preâmbulo afirma que "uma concepção comum destes direitos e liberdades é da mais alta importância

\footnotetext{
${ }_{18}$ Neste sentido, veja a citada Convenção de Viena de 1969, permitindo "recorrer a meios complementares de interpretação, designadamente aos trabalhos preparatórios e às circunstâncias em que foi concluído o tratado, com vista a confirmar o sentido resultante da aplicação do artigo 31, ou a determinar o sentido quando a interpretação dada em conformidade com o artigo 31 [...] deixe o sentido ambíguo ou obscuro; ou [...] conduza a um resultado manifestamente absurdo ou incoerente" (UNITED NATIONS, 1969, art. 32).
} 
para dar plena satisfação a tal compromisso" (UNITED NATIONS, 1948, preâmbulo).

Nestas palavras nós podemos perceber que a Assembleia Geral está estabelecendo uma ligação direta entre o "compromisso" na Carta (que é um tratado impondo obrigações jurídicas) e a elaboração dos direitos na Declaração que permitem uma "concepção comum" dos direitos e liberdades referidos na Carta. Esta linguagem sugere que os escritores da Declaração intentaram que a Declaração serviria como definição dos direitos contidos na Carta, ou seja, uma interpretação autoritária destes direitos. Desta maneira, a ligação estreita textual entre a Carta e a Declaração pode servir a elevar o status jurídico da Declaração como interpretação das obrigações anunciadas na Carta. Se existe qualquer dúvida quanto às intenções dos redatores da Carta, a minha teoria nos permite a resolver uma tal dúvida em favor desta compreensão do papel da Declaração porque ela fortaleceria a realização de princípios éticos fundamentais.

\section{O Status Jurídico da Declaração Como Resolução das Nações Unidas Que Tem Uma Força Jurídica Segundo a Carta}

Há uma segunda maneira na qual a Declaração é relevante à Carta das Nações Unidas. Segundo a Carta (UNITED NATIONS, 1945, art. 13, para 1), a Assembleia Geral tem o poder de fazer "recomendações" destinadas a "favorecer o pleno gozo dos direitos humanos e das liberdades fundamentais, por parte de todos os povos, sem distinção de raça, sexo, língua ou religião". Portanto, cada resolução, por virtude deste status concedido pela Carta, tem um grau de autoridade jurídica.

Mesmo se cada resolução constitui uma "recomendação," não seria no espírito da Carta que um Estado Membro ignorasse intencionalmente ou que agisse claramente contra uma tal recomendação. De fato, segundo as regras da Convenção de Viena sobre o Direito dos Tratados, cada Estado aderente a um tratado tem o dever de cumprir as suas obrigações "de boa-fé" 
(UNITED NATIONS, 1969, art. 26). Consequentemente, nós podemos concluir que cada resolução tem "autoridade jurídica persuasiva." Isto quer dizer que cada Estado Membro das Nações Unidas tem o dever de dar à Declaração "peso grande” nas suas decisões e políticas (LEPARD, 2010, p. 325-326).

Além disso, é geralmente reconhecido por Estados Membros das Nações Unidas que resoluções chamadas "declarações" são intentadas possuir um peso especial. Por exemplo, uma opinião emitida em 1962 pelo Departamento de Assuntos Jurídicos da Secretaria das Nações Unidas afirmou que "tendo em vista a maior solenidade e o maior significado de uma "declaração," ela pode ser considerada a criar, por parte do órgão a adotando, uma expectativa forte de que os membros da comunidade internacional a cumprirão" (UNITED NATIONS, 1962). No fim das contas, este status especial de uma "declaração" prove das atitudes dos Estados Membros si-mesmos. E finalmente, nós podemos concluir que, por causa da repetição frequente da DUDH por parte dos governos como documento especial que tem importância jurídica, esta declaração particular disfruta de um peso particularmente grande.

\section{O Status dos Direitos Humanos Proclamados na Declaração no Direito Internacional Consuetudinário}

Conforme discutido acima, o status particular dos direitos humanos especificados na Declaração como direito internacional consuetudinário é também controvertido. De acordo com a definição tradicional do direito internacional consuetudinário, uma norma torna-se uma norma de direito internacional consuetudinário quando os Estados do mundo agem de uma maneira consistente com a norma (referido a "uma prática geral") e quando eles agem assim porque eles acreditam que eles têm uma obrigação jurídica a seguir esta prática. A Comissão de Direito Internacional das Nações Unidas revisitou a questão de como identificar normas de direito 
internacional consuetudinário e de acordo com as recomendações de um relator especial sobre o assunto, Sir Michael Wood, adotou conclusões que, em geral, reafirmam esta definição. Estas conclusões foram aprovadas pela Assembleia Geral das Nações Unidas em dezembro de 2018. Particularmente, a conclusão 2, intitulada "Dois Elementos Constituintes," afirma que "[p]ara determinar a existência e o conteúdo de uma regra de direito internacional consuetudinário, é necessário avaliar se existe uma prática geral que é aceitada como lei (opinio juris)" (UNITED NATIONS, 2018b).

À luz desta definição, nós encontramos uma variedade de pontos de vista sobre o status das normas proclamadas na Declaração como direito internacional consuetudinário. Por um lado, conforme já mencionado, alguns especialistas mantêm que a Declaração não possui nenhum status jurídico como direito consuetudinário. Alguns deles apontam a ausência de prática consistente pela parte dos Estados em respeitando os direitos humanos. Eles podem também ter dúvidas que os Estados já acreditam que eles têm o dever jurídico de respeita-los. Por exemplo, Bruno Simma e Philip Alston (1988-1989) tem argumentado que normas de direitos humanos muitas vezes não podem satisfazer os critérios tradicionais pelo direito internacional consuetudinário porque muitos Estados não conseguem colocar esses direitos em prática e de fato os violam; estes juristas recomendam em vez que muitos direitos humanos podem ser considerados princípios gerais de direito.

Por outro lado, existem especialistas, organizações e conferências que argumentam que a Declaração em todo tem se tornado direito consuetudinário. Por exemplo, John Humphrey (1979, p. 29), o antigo diretor da Divisão dos Direitos Humanos das Nações Unidas na época da adoção da Declaração afirmou que "as provisões justiçáveis da Declaração, incluindo certamente, aquelas anunciadas em artigos dois a vinte-um inclusivos, agora têm adquirido a força de direito como parte do direito 
consuetudinário das nações". ${ }^{19}$ E a "Montreal Statement of the Assembly for Human Rights," adotada em 1968, declarou que a Declaração "tem ao longo dos anos ficado uma parte do direito internacional consuetudinário" (UNITED NATIONS, 1968, p. 95).

No meio destas opiniões, outros especialistas promovem a visão que é preciso empreender uma análise de cada direito proclamado na Declaração para determinar se há prática e opinio juris o suficiente para reconhecê-lo como direito consuetudinário. Bruno Simma e Philip Alston (1988-1989) se põem neste agrupamento. Um relatório preparado pela Associação de Direito Internacional sobre o status da Declaração no direito nacional e internacional adotou também a visão que alguns dos direitos proclamados dentro dela não satisfazem os requerimentos pelo direito consuetudinário porque eles são meramente aspiracionais (INTERNATIONAL LAW ASSOCIATION, 1994, p. 544). A reportagem argumentou que "parece-se difícil comprovar que os Estados reconheçam uma obrigação jurídica a garantir, por exemplo, férias periódicas com salário, a igualdade plena dos direitos na dissolução de um casamento, ou a proteção contra o desemprego" (INTERNATIONAL LAW ASSOCIATION, 1994, p. 544).

$\mathrm{Eu}$ tenho desenvolvido uma teoria nova do direito internacional consuetudinário que é consistente com a abordagem das fontes de direito internacional esboçada acima. ${ }^{20}$ Segundo esta teoria, uma norma fica uma norma de direito internacional consuetudinário quando os Estados do mundo, em geral, acreditam que seria desejável, agora mesmo ou no futuro próximo, ter um princípio jurídico ou uma regra jurídica exigindo, permitindo, ou proibindo certa conduta. A prática geral não é necessária, mas pode fornecer prova de uma tal crença. Ademais, se nós temos dúvidas concernentes às crenças de Estados, nós podemos considerar o efeito de uma norma proposta sobre a realização de princípios éticos fundamentais.

19 Veja também WALDOCK, 1965, p. 15.

20 Para uma explicação da aplicação desta teoria a normas de direitos humanos, veja LEPARD, 2010, p. 306-45; e LEPARD, 2017. 
Assim, o elemento fundamental do direito internacional consuetudinário é esta crença, ou seja, opinio juris, assim reconceitualizada (LEPARD, 2010, p. 8).

Portanto, a pergunta relevante hoje em dia é: "[o]s Estados geralmente acreditam que é desejável, agora mesmo ou no futuro próximo, reconhecer alguns dos direitos ou todos os direitos proclamados na Declaração como obrigações jurídicas obrigatórias ou persuasivas para todos os Estados na comunidade mundial?"

Segundo a minha teoria, nós podemos consultar uma variedade de fontes de evidência sobre as crenças de Estados sobre a questão de se é desejável reconhecer os direitos na Declaração como obrigações jurídicas para todos os Estados. Primeiro, nós podemos considerar o texto ele-mesmo; e nós temos visto que muitas expressões na Declaração indicam que os Estados que a adotaram acreditaram que deve existir uma obrigação jurídica a dar peso grande a estes direitos - uma crença evidenciada pelas referências na Declaração ao seu status como ferramenta de interpretação das obrigações jurídicas estabelecidas na Carta das Nações Unidas. Por exemplo, o preâmbulo da Declaração diz que ela é "um padrão comum de realização" por "todos povos e nações." Ela não permite exceções se um Estado não se acorda com os seus princípios. Para resumir, o texto sugere que os Estados acreditam que todos os Estados no mundo têm a obrigação jurídica persuasiva a garantir estes direitos.

Os recordes dos debates entre os Estados durante a elaboração da Declaração dão apoio a esta interpretação. Alguns Estados sugeriram que a Declaração tivesse uma autoridade persuasiva jurídica. Por exemplo, no debate plenário, o delegado da França "explicou que, enquanto a Declaração foi menos poderosa e obrigatória do que uma convenção, ela não teve um valor jurídico menor, porque ela foi incorporada em uma resolução da Assembleia Geral que foi capacitada a fazer recomendações; ela foi um desenvolvimento da Carta que teve trazido os direitos humanos no âmbito 
do direito internacional positivo" (UNITED NATIONS, 1950, p. 531-532). Ademais, conforme notado acima, os desenhistas da Declaração pretenderam que ela seria implementada por um tratado obrigatório.

Outros fatores aumentam a força da Declaração como prova de opinio juris. Por exemplo, a Declaração foi o resultado de uma discussão abrangente com diversos pontos de vista exprimidos por Estados representando culturas e sistemas de governo diferentes (GLENDON, 2001, p. 221-233). A adoção da Declaração não foi apressada e muito cuidado foi dado à sua elaboração. A votação sobre a Declaração foi quase unânime. Nenhum país votou contra; houve oito abstenções, vindo da União Soviética e seus aliados, da Arábia Saudita, e da União da África do Sul, que, respectivamente, achavam que a Declaração deveria dar mais ênfase ao princípio de soberania, que ela deu proteção demais à liberdade de religião, e que ela foi longe demais em protegendo a igualdade das raças. No entanto, estas críticas não causaram estes países a se opor à Declaração, indicando que eles acreditaram que em geral o reconhecimento dos direitos na Declaração foi desejável.

Ademais, segundo a minha teoria do direito internacional consuetudinário, o fato que a Declaração sustenta princípios éticos fundamentais, sendo relacionados com um princípio preeminente da unidade na diversidade, lhe dá mais influência na determinação de opinio juris.

Estes fatores pertencendo à época da adoção da Declaração lhe dão peso significativo na determinação de opinio juris. No entanto, a existência de opinio juris hoje depende das atitudes dos Estados perante o documento neste momento. Conforme revisado acima, há muitas provas da aceitação global da Declaração como uma afirmação de direitos que os Estados não podem ignorar e a qual eles devem dar um peso significativo. Estas provas 
incluem declarações de líderes mundiais em favor da Declaração, ${ }^{21}$ afirmações em muitas declarações de órgãos internacionais que a Declaração estabelece obrigações para todos os Estados, a inclusão de referências jurídicas à Declaração em constituições nacionais, e referências à Declaração em leis nacionais. Estes fatos tendem a apoiar a conclusão que os Estados em geral acreditam que é desejável reconhecer uma obrigação universal por parte dos Estados a dar à Declaração autoridade jurídica persuasiva.

Pode-se citar como exemplo de uma declaração internacional afirmando a autoridade da DUDH, complementando aquelas citadas acima, o Documento de Resultado de 2005 da Cimeira Mundial. Neste documento os chefes de Estado e governo reafirmaram "o comprometimento solene dos nossos Estados a cumprir suas obrigações a promover o respeito universal por, e a observação e proteção de, todos os direitos e liberdades fundamentais para todos de acordo com [...] a Declaração universal dos direitos humanos" (grifo nosso) (UNITED NATIONS, 2005, para. 120).

A esta lista de provas nós podemos adicionar opiniões várias da Corte Internacional de Justiça, que implicam que a Declaração estabelece um tipo de obrigação jurídica para todos os Estados. Por exemplo, no Caso de Reféns, de 1980, a Corte afirmou que "privar injustamente os seres humanos da sua liberdade e submetê-los a restrição física em condições de dificuldades é em si mesmo incompatível manifestamente com os princípios da Carta das Nações Unidas assim como os princípios fundamentais enunciados na Declaração Universal dos Direitos Humanos" (grifo nosso) (INTERNATIONAL COURT OF JUSTICE, 1980, p. 42, para. 91).

Ademais, muitos tribunais nacionais têm feito referência à Declaração como uma fonte de princípios jurídicos (muitas vezes em razão de provisões constitucionais), ou como uma ferramenta para interpretar constituições ou leis nacionais (HANNUM, 1995-1996, p. 296-310). Por exemplo, em alguns

21 Veja as afirmações descrevidas em INTERNATIONAL LAW ASSOCIATION, 1994, p. 539-541. 
casos a Corte Suprema dos Estados Unidos tem se referido à Declaração para sustentar normas particulares que a corte tem descoberto em fontes nacionais de direito, tal como a Constituição. ${ }^{22}$

No entanto, a Corte não clarificou se estas normas conseguiram o status de direito internacional consuetudinário. Ao mesmo tempo, há varios tribunais inferiores nos Estados Unidos que têm tratado a Declaração como "prova do conteúdo de direito internacional consuetudinário sobre os direitos humanos” (HANNUM, “1995-1996, p. 330). Por exemplo, na sua decisão em 1980 em Filartiga v. Pena-Irala, a Corte do Segundo Circuito de Recursos declarou que a norma proibindo a tortura havia se tornado uma norma de direito internacional consuetudinário "como evidenciado e definido pela Declaração Universal de Direitos Humanos". ${ }^{23}$

Todas estas provas indicam uma visão compartilhada entre os Estados e os seus órgãos, tais como tribunais, que a Declaração possui uma autoridade jurídica persuasiva, mesmo se todos os direitos nela não são completamente obrigatórios como direito internacional consuetudinário. Segundo a minha teoria, se existem dúvidas sobre as crenças de Estados, é apropriada fazer referência a princípios éticos fundamentais para resolvêlas. Nós devemos presumir que os Estados apoiam dando ao menos uma autoridade persuasiva a estas normas porque estas normas avançam a realização de princípios éticos fundamentais.

Esta conclusão quer dizer que cada Estado tem que dar peso grande a cada um destes direitos e descontar as razões que ele tem por não proteger o direito. E um Estado não pode cometer violações flagrantes do direito que efetivamente constituem não lhe dar nenhum peso. Ademais, quer dizer que nenhum estado é juridicamente justificado em ignorar completamente este direito, tal como em adotar leis que exigem horas de trabalho longas demais

\footnotetext{
22 Veja Kennedy v. Mendoza-Martinez, 372 U.S. 144, 161 n.16 (1963) (sobre as "consequências drásticas de apátridia" e o direito de cada indivíduo a manter uma nacionalidade); Zemel v. Rusk, 381 U.S. 1, 15 n.13 (1965) (sobre normas de devido processo). ${ }^{23}$ Veja Filartiga v. Pena-Irala, 630 F.2d 876, 882 (2d Cir. 1980) - tradução livre.
} 
- violando o direito garantido pelo artigo 24 da Declaração, que assegura a toda pessoa "descanso e lazer, incluindo a limitação razoável de horas de trabalho e férias periódicas com salário" (UNITED NATIONS, 1948, art. 24).

Ao mesmo tempo, para determinar se um direito particular anunciado na Declaração tem ficado completamente obrigatório como direito internacional consuetudinário, é preciso empreender uma pesquisa mais profunda nas atitudes de Estados respeito a este direito. E uma análise distinta é necessária para determinar se uma norma constitui uma norma de jus cogens ou se ela seja erga omnes (LEPARD, 2010, p. 331-345).

\section{O Status dos Direitos Humanos Proclamados na Declaração como Princípios Gerais de Direito}

Conforme discutido acima, "princípios gerais de direito" constituem uma terceira categoria de fontes de direito internacional segundo o Estatuto da CIJ. Qual a relação entre os direitos humanos identificados na Declaração e estes princípios? As fronteiras da categoria de "princípios gerais de direito" são incertas, mas com certeza a categoria abrange princípios gerais de direito nacional que são comuns e que caracterizam a maioria dos sistemas nacionais jurídicos, se não todos deles (LEPARD, 2010, p. 164-165).

O exame acima da influência da Declaração sobre constituições nacionais e leis nacionais geralmente sugere que quase todos os direitos na Declaração são reconhecidos em leis nacionais - seja como resultado de uma referência explicita à Declaração nessas leis, seja porque o direito ele-mesmo apareça nelas mesmo se o direito não é atribuído à Declaração explicitamente. Apesar das dificuldades associadas a pesquisar todas as leis de todas as nações tratando desses direitos, é provável que a maioria destes direitos - ao menos em princípio - sejam reconhecidos nas leis nacionais, 
apoiando a conclusão de que eles se enquadram na categoria de "princípios gerais de direito".

Ademais, há um segundo tipo de princípios gerais de direito atualmente reconhecida pela CIJ, aquela de "princípios gerais de direito internacional" (LEPARD, 2010, p. 166-167) Apesar das dificuldades de distinguir este tipo do direito internacional consuetudinário, que eu tenho abordado nas minhas escritas (LEPARD, 2010, p. 166-167), este tipo é muito importante e pode englobar princípios que são geralmente aceitos pelos Estados do mundo em documentos internacionais (incluindo tratados e declarações das Nações Unidas).

Já revi as provas da aceitação da Declaração e da sua influência moral, política e jurídica. À luz desta influência, juntos com a aparência dos princípios da Declaração dentro de leis nacionais, podemos concluir que os princípios na Declaração constituem também princípios gerais de direito internacional. Então, todos os direitos proclamados na Declaração devem ser, atualmente, considerados princípios gerais de direito internacional. Novamente, nós devemos resolver qualquer dúvida em favor do reconhecimento deles, porque eles promovem a realização de princípios éticos fundamentais, e particularmente a realização da dignidade humana.

Finalmente, eu tenho sugerido que certos "princípios gerais de direito moral" possam ser considerados "princípios gerais de direito" dentro da definição no Estatuto da CIJ (LEPARD, 2010, p. 165; LEPARD, 2002, p. 106-109). Este tipo de princípios tem sido reconhecido implicitamente pela CIJ na sua opinião consultiva de 1951 sobre reservas à Convenção sobre o Genocídio, na qual a Corte afirmou que a proibição do genocídio foi um princípio "reconhecido por nações civilizadas como obrigatório por Estados, mesmo sem qualquer obrigação convencionais [isto é, estabelecida por um tratado]". A Corte também fez referência a "direito moral" e aos "princípios mais elementares de moralidade" (INTERNATIONAL COURT OF JUSTICE, 1951, p. 23). 
A Declaração pode servir como prova da natureza moral séria dos princípios anunciados dentro dela. Eu tenho argumentado que não necessariamente todos os princípios na Declaração possam ser classificados automaticamente como "princípios gerais de direito moral" porque esta classificação significa um status muito elevado no plano moral e também exige que o princípio seja especificado apropriadamente em se transformando de princípio moral para princípio jurídico (LEPARD, 2002, p. 106-108).

No entanto, eu tenho proposto que ao menos os princípios na Declaração que possam ser considerados "constrangedores" ou "essenciais" em relação a princípios éticos fundamentais devem ser considerados ter conseguido este alto nível. Eu tenho definido princípios "constrangedores" como princípios éticos fundamentais que merecem um peso especialmente grande em relação a outros princípios éticos por causa do seu relacionamento direto e imediato ao princípio preeminente da unidade na diversidade.

No mesmo sentido, eu tenho definido princípios "essenciais" como princípios que são tão estreitamente ligados ao princípio preeminente da unidade na diversidade que eles mereçam o peso maior e então não podem ser limitados ou ultrapassados por outros princípios éticos (LEPARD, 2002, p. 40). Um exemplo de um princípio de direito moral baseado em um princípio ético constrangedor é o princípio segundo o qual governos, organizações internacionais, e outros atores não possam violar deliberadamente direitos humanos essenciais (LEPARD, 2002, p. 106-107).

Diz respeito a esta definição, direitos humanos essenciais são aqueles direitos humanos reconhecidos no direito internacional contemporâneo (tal como a Declaração) que moralmente merecem o maior peso porque eles constituem umas das exigências mais essenciais pelo gozo de dignidade humana igual e são tão estreitamente ligados ao princípio preeminente da unidade na diversidade. Por causa da sua importância, normalmente eles 


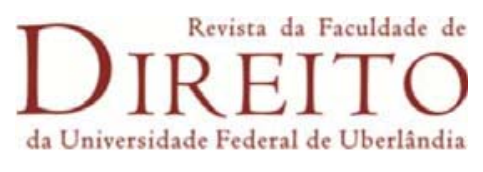

devem ultrapassar moralmente qualquer motivo para não os respeitar (LEPARD, 2002, p. 57-58). Esta categoria superior inclui direitos humanos tais como o direito à vida e à seguridade física, o direito à subsistência (incluindo à alojamento e à alimentação), e o direito à liberdade de fazer escolhas morais (LEPARD, 2002, p. 59 - fig. 3).

\section{Conclusão}

Neste artigo eu busquei esclarecer o status jurídico da Declaração e dos direitos proclamadas nela no direito internacional contemporâneo. Por que a determinação deste status jurídico é tão importante? Há muitas razões, mas cabe destacar duas em particular. Em primeiro lugar, nós presenciamos, hoje em dia, inúmeras violações massivas de direitos humanos em muitos países. O problema destas violações está crescendo. Para combatê-lo, é essencial estabelecer as bases jurídicas pela proteção de direitos humanos em terreno firme.

Em segundo lugar, e talvez mais inquietante e assustador, alguns líderes hoje põem em questão a validade de alguns direitos proclamados na Declaração e mesmo o conceito de direitos humanos universais. Esta atitude encontra apoio em alguns movimentos baseados sobre o "populismo" ou mesmo no "neofascismo" que visam a elevar a posição de um grupo social (muitas vezes povos brancos de origens europeias) sobre aquela de outros grupos desfavorecidos (tal como minorias e povos negros). ${ }^{24}$

É importante, portanto, estabelecer que os direitos na Declaração sejam enraizados no direito internacional para resistir estas tentativas de jogar fora alguns direitos, e mesmo a própria Declaração. Eu tenho proposto

\footnotetext{
${ }^{24}$ Sobre o crescimento do populismo e do neofascismo como ameaças aos direitos humanos atualmente, veja ALBRIGHT, 2018, e a palestra da Professora Micheline Ishay, Professor da Universidade de Denver, pronunciada na Faculdade de Direito da Universidade de Nebraska o 26 novembro 2018 a uma conferência comemorando o septuagésimo aniversário da Declaração Universal dos Dirietos Humanos (ISHAY, 2010 p. 648 - em que se discute a possibilidade, no futuro, de "reavivamentos de totalitarismo selvagens no mundo desenvolvido" (no original: "revivals of savage totalitarianism in the developed world").
} 
aqui uma teoria que possa ajudar os líderes do mundo e juristas a defender estes direitos no plano jurídico por assegurar a realização deles mais eficazmente.

\title{
Referências
}

ALBRIGHT, Madeleine. Fascism: a warning. New York: HarperCollins, 2018.

\begin{abstract}
ANDORRA. Constituição. $\quad 1993 . \quad$ Disponível em https://www.constituteproject.org/constitution/Andorra_1993.pdf?lang=en. Acesso em: 10 jun. 2020.
\end{abstract}

CONSELHO DA EUROPA. Convenção para a Proteção dos Direitos do Homem e das Liberdades Fundamentais. 1950.

GLENDON, Mary Ann. A World Made New: Eleanor Roosevelt and the Universal Declaration of Human Rights. New York: Random House, 2001.

GOODRICH, Leland M., HAMBRO, Edvard, SIMONS, Anne Patricia. Charter of the United Nations: Commentary and Documents. 3d ed. New York: Columbia University Press, 1969.

HANNUM, Hurst. The Status of the Universal Declaration of Human Rights in National and International Law. Georgia Journal of International and Comparative Law, v. 25, 1995-1996, pp. 287-397.

HUMPHREY, John P. The International Bill of Rights: Scope and Implementation. William and Mary Law Review, v. 17,1976, pp. 527-541.

The Universal Declaration of Human Rights: Its History, Impact and Juridical Character. In: RAMCHARAN, B. G. Human Rights: Thirty Years after the Universal Declaration: Commemorative Volume on the Occasion of the Thirtieth Anniversary of the Universal Declaration of Human Rights. The Hague: Martinus Nijhoff Publishers, 1979, pp.21-37.

INTERNATIONAL COURT OF JUSTICE. United States Diplomatic and Consular Staff in Tehran (United States of America v. Iran). 1980. Disponível em: https://www.icj-cij.org/en/case/64. Acesso em: 20 abr. 2020

Advisory Opinion - Reservations to the Convention on the Prevention and Punishment of the Crime of Genocide. 1950. Disponível em: https://www.icjcij.org/en/case/12. Acesso em: 20 abr. 2020

INTERNATIONAL LAW ASSOCIATION. Buenos Aires Conference (1994). Committee on the Enforcement of Human Rights Law. Final Report on the Status of the Universal Declaration of Human Rights in National and International Law. Report of the Conference. London: W. Clowes and Sons, 1994.

ISHAY, Micheline R. The Sixtieth Anniversary of the Universal Declaration of Human Rights: Exploring the Past, Anticipating the Future. Transnational Law and Contemporary Problems, v. 19, 2010, pp. 639-54.

KELLY, J. Patrick. The Twilight of Customary International Law. Virginia Journal of International Law, v. 40, 2000, pp. 449-543.

LAUREN, Paul Gordon. The Evolution of International Human Rights: visions seen. 3rd. ed. Philadelphia: University of Pennsylvania Press, 2011 


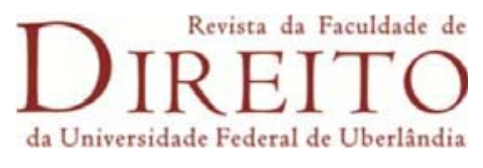

LAUTERPACHT, Hersch. International Law and Human Rights. N.P.: Archon Books, 1968.

LEAGUE OF NATIONS. Pacto da Liga das Nações. 1919.

LEPARD, Brian D. Customary International Law: A New Theory with Practical Applications. New York: Cambridge University Press, 2010.

Towards a New Theory of Customary International Human Rights Law. In: LEPARD, Brian D. (Ed.). Reexamining Customary International Law. New York: Cambridge University Press, 2017, pp. 233-65.

Rethinking Humanitarian Intervention: a Fresh Legal Approach Based on Fundamental Ethical Principles in International Law and World Religions. University Park: University of Pennsylvania Press, 2002.

MORSINK, Johannes. The Universal Declaration of Human Rights: Origins, Drafting, and Intent. Philadelphia: University of Pennsylvania Press, 1999.

ORGANIZAÇÃO DOS ESTADOS AMERICANOS.Convenção Americana sobre Direitos Humanos. 1969.

PORTUGAL. VII Revisão Constitucional. 2005. Disponível em: http://www.parlamento.pt/LEGISLACAO/Paginas/ConstituicaoRepublicaPortuguesa.aspx. Acesso em: 10 jun. 2020.

SIMMA, Bruno; PHILIP Alston. The Sources of Human Rights Law: Custom, Jus Cogens, and General Principles. Australian Yearbook of International Law, v. 12, 1988-1989, pp. 82-107.

STAMATOPOULOU, Elsa; DANIELI, Yael; DIAS, Clarence J. Introduction. In: DANIELI, Yael; STAMATOPOULOU, Elsa; DIAS, Clarence J. The Universal Declaration of Human Rights: Fifty Years and Beyond, Amityville, N.Y.: Baywood Publishing Co., 1999, pp. 149-61.

UNITED NATIONS. Yearbook of the United Nations, 1948-49. U.N. Sales No. 1950 I.II. Lake Success, N.Y.: United Nations Department of Public Information, 1950.

. Charter of the United Nations. 1945.

. Conselho Econômico e Social. Res. 5(I). 1946.

. Assembleia Geral. Doc. A/60/L.1. 2005.

Humanos. 1948.

Assembleia Geral. Res. 217A (III) - Declaração Universal dos Direitos . Assembleia Geral. Res. 2145 (XXI). 1966c.

Assembleia Geral. Declaração das Nações Unidas sobre os Direitos dos Povos Indígenas. 2007.

. Assembleia Geral. Doc. A/2929. 1955.

. Assembleia Geral. Doc. A/73/53. 2018a.

. Assembleia Geral. Res. 73/203. 2018b.

. Assembleia Geral. Montreal Statement of the Assembly for Human Rights. 1968.

In: Journal of the International Commission of Jurists, v. 9, 1968, pp. 94-109.

. Departamento de Assuntos Jurídicos. U.N. Doc. E/3616/Rev.1. 1962. 
Comissão de Direito Internacional. Doc. A/CN.4/L.908: A Identificação de Direito Internacional Consuetudinário: Texto das Conclusões Provisórias como Adotadas pelo Comitê de Redação na Segunda Leitura. 2018b.

Pacto Internacional sobre Direitos Civis e Políticos. 1966a.

1966b.

Pacto Internacional sobre Direitos Econômicos, Sociais e Culturais.

Convenção sobre os Direitos das Pessoas com Deficiência. 2006.

. Convenção de Viena sobre o Direito dos Tratados. 1969.

UNITED STATES. Iraq Sanctions Act of 1990. Nov. 5, 1990.P.L. 101-513, Title V, §§ 586-586J, 104 Stat. 2047-2054.

WALDOCK, Sir Humphrey. Human Rights in Contemporary International Law and the Significance of the European Convention. In: WALDOCK, Sir Humphrey. The European Convention on Human Rights. London: Stevens and Sons on behalf of the British Institute of International and Comparative Law, 1965, pp. 1-23

Artigo recebido em: 05/02/2020.

Aceito para publicação em: 26/02/2020. 